\title{
Historia magistra vitae
}

Неретина С. C., доктор философских наук, Институт философии РАН, Москва, главный научный сотрудник, профессор, главный редактор журнала Vox, abaelardus@mail.com

Аннотация: в статье ставится вопрос о понимании истории не как синтеза изначально древнегреческого понимания мира, мира космического порядка и иудейского олама, а палимпсеста, где сквозь написанный текст просматривается стертый другой текст так, что проявленными оказываются два несхожих образа мира. Автор просматривает возможности такого понимания истории через тексты «Об ораторе» Цицерона, «Схоластическую историю» Коместора и через фрагмент «Прослогиона» Ансельма Кентерберийского, который включил в свое произведение возражение на него некоего монаха Гаунилона. Идея мира В.В.Бибихина представляется вариантом разрешения проблемы двойственного понимания истории.

Ключевые слова: история, мир-космос, мир-олам, разум, речь, метафора, природа, потоп, разрыв, перформативность.

\section{Исторический палимпсест}

Когда говорится об истории, о высказывании относительно истории, о рассказе об историческом событии, то всегда перед историком или философом вставала апория, касающаяся способа, каким разрешалась проблема мгновенности превращения слова в дело, как была возможна перформативная речь, отождествляющая слово и поступок. В свое время этим занимался Дж. Остин, поставивший проблему единства локутивного и иллокутивного актов. Те, кто занимается средневековой философией и, соответственно, проблемой Слова, знают, что человеческая речь отличается от божественной именно разрывом между речью и делом, производящимся после сказанного. Это собственно обусловлено проблемой времени. Дело, возникающее как следствие речи, связано с прошлым, настоящим и будущим, в то время как перформативная речь связана только с настоящим, имеющим дело с выражением самой сути. Истинно перформативные высказывания одновременно описывают совершение некоторого действия и самим актом произнесения выполняют его. Не сведущий в перформативности Августин в диалоге «Об учителе» объяснял, как можно человеку прояснять значения слов. Чтобы понять, что такое «ходить», нужно начать ходить и одновременно говорить, что вот то, что сейчас делается, называется «ходить». Но акт хождения и акт говорения - разные акты. Если же надо объяснить слово «говорить», то надо начать говорить и в то же время говорить, что то, что сейчас производится, называется говорением [Аврелий Августин, 1998, с. 175]. То есть здесь одна-единственная фактичность, один акт говорения. История непосредственно 
связана и с единством слова и дела (единство замысла в истоке, принадлежащего любому творцу), и с разрывом между ними во времени, свойственным творению, порождающим собственно историю. Поскольку же история рассматривается как стремление к исчерпанности, т. е. к единству (совпадению) точек начала и конца, то разум при этом способен впасть в жесткий логицизм без нравственных ориентиров, при опоре на голый технически правильный расчет, от которого его могут избавлять свободные творческие акты мышления.

В начале европейского мышления история, как известно, была представлена, вопервых, как одна из муз, идущих за Аполлоном со свитком в руках, во-вторых, производной от корня «истор», под которым понимался третейский судья у Гомера, оправдывающий выражение «суд истории» [Неретина С. С., 2018, с. 27-30], — так назывался фильм, который показывали во время оттепели по разным закрытым учреждениям о выпущенном на волю Василии Витальевиче Шульгине, который был лидером Государственной думы, одним из организаторов белого движения, антисемит, член антисемитских организаций и одновременно защитник Бейлиса, дай бог всем быть такими антисемитами, - в-третьих, этот корень входил в слова, означающие любой крюк, который каким-то образом захватывал вещи.

Это если смотреть в начало пока еще даже не европейской истории, которая в то время не была центром сознательного притяжения мысли, ведь и Геродот не писал «Историю», это по́зднее название. Их, античных мифологов-мыслителей, интересовал космос. Но они тесно были связаны с восточными соседями, у которых праучреждающим актом образования народа, обусловившим «характер учреждающего его индивида» [Савин А.Э., 2018, с. 69, 75], был не Космос (порядок, украшение), а 'олам ха-ба, «грядущий мир», и 'олам ха-зе, «этот мир» - как видим, в названии нет ни порядка, ни украшения, но есть указание времени. Если по древнегреческим представлениям (например, Гесиода) золотой век был вначале, то, согласно мнению рабби Иоханана бар Наппахи (используем пример из энциклопедии), золотой век - в будущем. Потому время в 'олам ха-ба течет не из будущего, как считал Аврелий Августин, а из прошлого, оно было призывом того, чего «никакое око не видело» (Ис. 64:3; русский перевод 64:4). Когда оба понятия наложились друг на друга - это случилось во время интенсивных переводов Библии на греческий язык, а затем и на латинский язык в первые века новой эры, античной философии как целому пришел конец. «Время изменилось», - сказал Августин, настала пора христианства.

Впрочем, и оламу пришел конец: исследований, как мне написал Илья Дворкин, нет, как нет и хороших энциклопедических статей. Как сообщает А. Э. Савин, исследовавший раннего Гегеля, тот предположил, что после потопа произошел разрыв с природой, и недоверие к природе и к другим людям было основанием для рождения религии трансцендентного Бога и началом того, что потом было названо отчуждением и началом истории, за которую отвечает человек, и только он [Савин А. Э., 2018, с. 74]. Иудеохристиане (первоапостольская община до вхождения в нее «эллинов») признавали мессианский статус Иисуса Христа при сохранении значимости Моисеева Закона. Но они исчезли после 70-го года. Христианство распространялось среди населения, не жившего по иудейским обычаям. Когда мир стал пониматься как космос, то история, естественно, стала пониматься как нечто одно, известное как разворачивание и осуществление 
Божественного Провидения. В конце 60-х - начале 70-х годов XII в. канцлер Собора Парижской Богоматери Петр Коместор написал в «Схоластической истории» о таком плане творения мира: «У Бога-художника перед очами вся материя для мироздания», «вначале дом был в Мыслях Мастера, затем он воплощался материально, затем сущностно, когда у дома появляется собственная структура... К предведению Бога относится вид дома, к творению - материал и сущность <..> Писание объясняет шестидневное творение мира, делая три различия: творение, украшение, расположение» [Неретина С. С., 1993, с. 108, 110]. Историю христиане и считают как непоколебимо состоявшуюся по таковому Божественному плану. Но такую ли историю имели в виду ветхозаветные иудеи? Ибо перед нами соединение старых античных начал с Библией, где они вряд ли имелись в виду. Да и написана «Схоластическая история» через 20-25 лет после второго крестового похода и примерно за 20 лет до третьего, когда от антисемитизма было не укрыться. Мир представал не пустыней, которую надо пересечь, а великолепным дворцом для Бога-Владыки-Короля [Неретина С. С., 1993, с. 111-119]. Этот мир сразу расчетверился на: 1) мир вечных сущностей - эмпиреи, 2) чувственный мир, 3) верхнюю оболочку земли, 4) человека как микрокосм. Последние три временные, обладающие движением и эфемерные. Это деление, считает Коместор, соответствует философским делениям, при том, что «философ не постигает эмпиреев» [Неретина С. С., 1993, с. 127]. Эмпиреи - держащее и воздержное, чистое (mundus), этот мир вечен (sempiternus), другой — временно вечен (temporaliter aeternus). Жесткое деление надвое - обычное для Средневековья деление - дано в книге, долгое время, вплоть до XVII в., почитавшейся за учебник.

Радикально на двойственность истории, как мы видели, обратил внимание Гегель. В наше время о двойственности мира (того и этого) писал Бибихин. Но Бибихин как раз противится гегелевскому восприятию. Он пишет о восточном мире (Псевдо-Дионисий Ареопагит) как о мире покоя, а о западном - как о событии, речь о различии внутри европейского мировидения, но и здесь очень существенные наблюдения. Судя по всему, Бибихин тоже обратил внимание на постоянное воспроизведение исторического палимпсеста. Он излагает мнение одного из культурологов, который предлагает присоединить «к принципу статики еще и принцип динамики», чтобы «получилась более совершенная система, без недостатков прежних слишком статических систем» [Бибихин В. В., 1995, с. 78-79]. И он вовсе не исключает, хотя об этом не пишет, ни мираолама, ни мира-космоса, противопоставленных друг другу. У него время - иное. Оно то, оно само бытие, которое в прошлом ли, в будущем вернет нам то, что унесло. Суть времени и есть сама суть [Бибихин В. В., 1995, с. 82]. В самом событии мира есть завораживающая тишина, на что, как ни спорили, обращали внимание все пишущие о мире, входящем или не входящем в историю. А время всегда иное. Оно-то и позволило описать себя и через «полноту времен, век-эон (слово того же происхождения, что наше «юный»), исполнение времени, когда время станет одновременно и возвращением, и другим, - это старое название мира. «Мир сей» и «век сей» в Евангелии одно и то же» [Бибихин В. В., 1995, с. 93].

В библейском употреблении, как пишет Бибихин, мир-век, космос-эон - это разные вещи. «Прежде всего - прекрасное творение Бога. “Мир [космос] через Него 
[Бога] начал быть". < ..> Мир создан таким, что Бог говорит о нем, что он хорош, и любит мир, свое создание; о том, чтобы судить такой мир, не может быть речи. <..> Вот мир в исконном библейском смысле, чудесное и непостижимо совершенное» [Бибихин В. В., 1995 , с. 94], с которым разминулся человек. И вот тогда возник «мир сей», отколовшийся от того божественно-прекрасного мира. Этот раскол, по Бибихину, абсолютный,

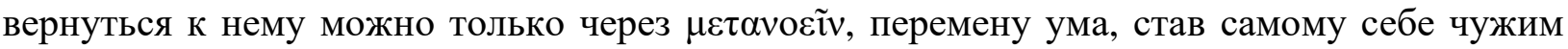
[Бибихин В. В., 1995, с. 96-97].

Средневековое (коместорово) отношение к Божественному миру как к чистоте (о чем говорит и Бибихин) и к земному как временному и человеческому, греховному накладывалось на свободно разворачивающуюся библейскую историю, всю между тем нацеленную на грядущее, прекращенную в один момент холокоста. Вряд ли в этом случае возможно говорить о синтезе изначально древнегреческого понимания мира, мира космического порядка и иудейского - грядущего ли или этого мира. Скорее перед нами палимпсест, где сквозь написанный текст просматривается стертый другой текст. Соединение оказалось гремучим. Мы имеем дело с разными смысловыми структурами. И это есть в философии Гегеля, в его интерпретации времени истории.

Грядущее (не будущее), как и «прошлое», предполагают не столько «быть», сколько «идти», приход же предполагает некое содержание, по ходу меняющееся, имеющее некое прошлое у этого грядущего, которое оно несет с собой. Требования порядка - это требования следовать космической устойчивости, несменяемой истории, не меняющейся истории-оламу, не грядущему. Почти незамеченно произошла подмена понятий, принятая, разумеется, не всеми, но и не всегда по злому умыслу. История, понятая как порядок, не может не быть magistra vitae. Олам оказался подмят, как, впрочем, (надолго) и сам иудаизм.

История, оказалось, может быть выстроена, структурирована. Считая, что в рассуждениях об истории мы опираемся на первоисточники, мы на деле пишем симулякры, у которых нет оригиналов, они часто оказываются подделанными. М. Я. Гефтер в 1970-е годы часто говорил о кухонных шепотах как об истинном документе, выражая полное недоверие к написанным источникам («чего стоят протоколы “троек” 1030-х годов!»). Проблема, поставленная постмодернистами, состоит в том, что многое непроговоренное или проговоренное симулятивно, оставляет позади себя промолченное и еще-не-обдуманное, но существующее, и это молчащая мысль когда-то соберет свою энергию и грянет громом, найдя верные слова. Бибихин предлагает иное отношение к истории, обратив внимание на мир, с которым история, как он пишет, завязана в один узел. Она «имеет дело с миром, она не в одном из своих планов, а по существу мировая. Историческое событие - всегда событие мира. Не человеческого только. Наука смотрит в далекие части Вселенной, и те пространства принадлежат истории, потому что если не они сами, то по крайней мере их смысл входит в историю, и история не может кончиться, пока далекие звезды остаются загадкой. Если человечеству придется уйти, когда построенные наукой вопросы будут еще оставаться вопросами, случится не конец истории, а ее срыв. В историю мир вовлечен так, что она завершится только в целом мире» [Бибихин В. В., 1995, с. 99]. 


\section{История в понимании Цицерона}

Но в Риме история как предмет изучения еще только рождалась. Она действительно могла считаться учителем жизни, ибо связывалась с речью, как потом будет связываться и в христианстве. Связал историю с речью Цицерон, и это во многом объясняет его авторитет среди христиан. Это часть речи и сама речь. Нет речи - нет истории. Вот только как понимать слово «magistra» («magister»).

Historia magistra vitae, история - учительница жизни. Это сказал Цицерон в трактате «Об ораторе». Полностью определение звучит так: «А сама история - свидетельница времен, свет истины, жизнь памяти, учительница жизни, вестница старины?» [Цицерон, «Об ораторе», 9 (36)].

При этом стало ясно, что наше понимание слова «магистр», «учитель» или в данном случае «учительница» не вполне выражает суть дела, ибо это слово выражает «что-то большое» (оно производное от magnus, откуда и «маг»). Это значит, что история рождается как magistra - как «что-то большое» - в самый момент речи, это не указующий перст, а тропологически разворачивающаяся речь, логика поворота. Это не просто метафора, метонимия, ирония и пр., хотя Цицерон говорит и о художественно выстроенной истории, и о «голой». Это возможность полной смены позиций, вызванной и знанием того молчания, того помысленного, но непроговоренного или умолчанного, и новыми намеками на нечто невысказанное.

Называя многие виды речи, Цицерон говорил не просто о том ее смысле, который подразумевал предмет ради удовольствия слушателей, но это уже и событие (со-бытие!), которое вызывает интеллектуальный шок. Он приводит в пример Исократа и так называемых софистов, Геродота и Фукидида, Ксенофонта и Аристотеля - т. е. он называет философов, которые «первые, по словам Феофраста, дали истории такой толчок, что после них она уже могла посягать на более обильную и пышную речь» [Цицерон, «Оратор», 39], т. е. на большее.

Чем отличается, по Цицерону, речь (т. е. ораторствование) от философии, софистики, истории, поэзии? Но независимо от различий, 1) все это - речь, понятая не только как инструмент: это 2) то, внутри чего рождаются способы говорения как именно такие, т. е. как философия, софистика и история, которые можно назвать родами говорения. Эти четыре стиля, как тогда говорили, или четыре жанра он объединяет, отдавая первенство философии, которая лежит в основе любой правильной речи и которую он предлагает назвать беседой, изначально полагая философию диалогичной. Историей же, разберем подробнее, называется «жизнь памяти», память же, тетоria, тесно связана с умом. И если философия задает принципы, то история предоставляет возможность их последовательно проговаривать и развивать. Это как бы две стороны, два способа умного видения.

Отличие истории от философии состоит в том, что история стремится $\kappa$ непрерывности и плавности, а философия - к остроте и силе [Цицерон, «Оратор», 20 (66)]. В обоих случаях речь идет о начале, которое сдержанно и богато острыми мыслями. Складывается иногда впечатление, что Цицерон пытается философию отличить 
именно от истории, а не от риторики, которой посвящен трактат, ибо пишет, что «повествование - правдоподобное, изложенное ясно, речью не исторической, а близкой к обыденной» [Цицерон, «Оратор», 36 (124)]. И в этом — все различие.

Если пытаться понять, как в начале христианской эры философия привязала себя к религии, как философские термины (например, «двусмысленность», частый термин у Цицерона) стали определять связи звуков и вещей (как и сам термин «звук», получивший у Цицерона важнейшую роль относительно имени) в религиозных текстах, то Цицерона, которого мыслители западного Средневековья, как известно, считали своим учителем, не могли не читать в свете понимания истории и как олам, и как космос. Ибо Цицерон дал определение истории, в начале эры еще не выполнявшей функции порядка и украшения. В Средние века этот термин появился поздно. Он редок у Августина. У Абеляра только в «Истории моих бедствий», где он означает последовательный перечень его несчастий, у Коместора, учившегося у Абеляра, - в уже упорядоченной «Схоластической истории», где повествования четырех евангелистов лишились личностных особенностей изложения и стали представлять один последовательный рассказ о жизни Христа. У Гийара де Мулэна - в «Исторической библии», вернувшей труду Коместора повествовательную свободу библейского слова, поскольку он восстановил и евангелия, и другие библейские книги, исключенные Коместором, как ему казалось, из-за повторов. В основном писали хроники и комментарии, которые по жанру не история. Но для истории бытовало именно определение Цицерона!

Речь, средоточием смысла которой является философия, выражалась именно исторически, через, напомним, плавное, последовательное изложение, она должна была использовать все возможные способы выражения (рупор человеческой жизни). История как выражение олама, движения к будущему золотому веку - царству Бога, должна была бы вступить в противоречие с космосом, который изначально представлял собой порядок. Теоретическая работа Гийара де Мулэна, повторявшая за Коместором его описания космического устройства, вступала в противоречие с его практической работой, восстанавливающей библейское, отнюдь не последовательное движение повествования.

У Цицерона на космическую идею работают такие способы выражения, как: 1) задержание; 2) умаление, осмеяние; 3) отступление; 4) предуведомление, propositio; 5) подытоживание, complexio; 6) возвращение; 7) повторение; 8) силлогизм, conclusio; а на оламическую идею, рождая своего рода единство апперцепции, такие как: 9) вопрошение; 10) подсказывание; subiectio; 11) ирония; 12) сомнение; 13) разделение; 14) свободоречие; 15) просьба, мольба; 16) негодование; 17) попрек; 18) умолчание, praeteritio.

Смысл истории - в постижении истины, как и у философии. В силу такой тесной связи истории с философией, свободы мысли и свободы наррации «то большое», которое есть история, не может быть просто чем-то традиционным и неизменным, хотя, как и философия, оно может передавать или умалчивать мысль и смысл. Диалог «Об ораторе» - то, можно сказать, теоретическое рождение истории, рождение понятия истории.

Как сказал один из героев трактата Антоний, «история только сейчас выступила на свет в нашей литературе, littera» [Цицерон, «Об ораторе», 13 (55)]. Мы присутствуем как бы при начале истории как жизненного основания, как буквы жизни. Литература - это ведь «буквализм», а буквы имеют такую особенность: меняться местами. Уже в силу этого 
она не может быть постоянной и неизменной. Здесь от перемены мест слагаемых меняется все. Это другая речь. Не арифметика.

Утраченное значение термина, конечно, мало что меняет в нашей жизни, мы не всегда ощущаем потерю слов. Но уходит мир. Старый мир (античность, Средневековье) воспринимается в наших понятиях, представлениях, восприятиях. Он кажется просто прошедшим временем, подобным той минуте, что прошла вот только что, пока пишется фраза. Но ушло не просто время, а именно мир, иное бытие, по-своему окрашенное, со своим физическим зрением и умозрением. Мы как бы его изучаем, а он стоит рядом и попрежнему живет своей жизнью. История, определенная Цицероном (106 до н. э. - 43 до н. э.), действительно изначально выступала как наставник, дерзающий научить нас памяти, умению высвободить из забвения другой мир, возвестить о нем в двух смыслах: как нашего прошлого и как нашего иного. И прошлым, и иным был, скажем, захват Помпеем Великим Иудеи в 63 г. до н. э. Именно в этом году Цицерон стал консулом. Число евреев в Риме стало значительным. В 59 г. до н. э. Марк Туллий Цицерон говорил о том, что евреи заполняют римские суды (см. ст. «Римская литература»). Еврейское население Рима увеличилось в эпоху правления Юлия Цезаря, который считал евреев одним из элементов, связующих Римское государство, и освободил их от ряда ограничений, обязательных для других представителей чужих культов. В 1 в. до н. э. евреи селились в основном на правом берегу реки Тибр, где образовался еврейский квартал. Младший современник Цицерона Гораций упоминает евреев и еврейские обычаи в своих сатирах, называя еврейскую теологию печальной. В это время, если судить по римской литературе, как сообщает об этом Еврейская электронная энциклопедия, вражды к евреям не чувствуется.

У самого Цицерона евреи упомянуты в двух речах - 59 г. и 56 г. до н. э., где он, конечно, называет иудаизм варварским суеверием, но это скорее объясняется тем, что Цицерон выступал в суде на стороне их противников. Идеологический антисемитизм римских мыслителей проявляется позже, в 1 в. н. э. Сенека Младший видел в евреях носителей зла, чьи обычаи распространяются на весь мир, «превращая побежденных в победителей» ${ }^{1}$.

Я специально ссылаюсь на энциклопедические, т. е. известные факты, в том числе более позднего времени, чтобы показать, что в Риме образованные люди, ораторы, историки, политики интересовались обычаями и религией завоеванной страны. Диалог же «Об ораторе» был написан в 55 г. до н. э., т. е. после захвата Иудеи. Не исключено, что понимание олама как грядущего мира если и не коснулось общего взгляда на мир, то вошло в обычай риторики, понятой через вопрошание, субъектность, сомнение, свободоречие и мольбу - через некоторое время в христианстве эти речевые способности станут обозначать модусы духовного и душевного совершенствования, образовав ту самую странную импликацию, о которой говорилось выше. Если же учесть ее (речи и истории, речи как истории) тесную связь со Священным писанием, то так понятая история не утратила и до сих пор своего значения, а следовательно, она остается

1 См.: Римская литература // Еврейская Электронная энциклопедия. Электронный ресурс: https://www.google.ru/url?sa=t\&rct=j\&q=\&esrc=s\&source=web\&cd=\&ved=2ahUKEwjO2NK02L_0AhXrk4sKHb W1Avw4ChAWegQIFRAB\&url=https\%3A\%2F\%2Feleven.co.il\%2Fdiaspora\%2Fcommunities\%2F13523\%2F\&us g=AOvVaw1Gg2VW72aUEBC8dnOpPogP. (Дата обращения: 30.11.2021.) 
наставницей-учительницей, понятой как то, что всегда больше того, что говорится. В противном случае это не история.

В этом случае вспоминается «Прослогион» Ансельма Кентерберийского, в котором это «большое» двуосмысливается. Это, с одной стороны, то, больше чего нельзя помыслить, т. е. то, что имеет прямое отношение к Богу, но это и то, о чем можно солгать (возражение Гаунилона). Монах Гаунилон, возражая Ансельму, пишет, что «подобным образом я имею в уме и ложное, и само по себе вообще никак не существующее» [Ансельм Кентерберийский, 1995, с. 147]. Достоверно неизвестно, что такое то, что можно иметь в мышлении как нечто ложное и сомнительное, и потому я не говорю, что мыслю или имею в мысли это, но что я его понимаю и имею в интеллекте, мыслю или имею в мышлении. Когда Гаунилон говорит, что все, что мы слышим или выдумываем, ум воспринимает как истинно существующее, то, без сомнения, одно дело - это действительно существующее ${ }^{2}$, другое дело - интеллект-понимание, которым нечто постигается в его сути. Здесь нет тождества. Есть две стратегии - быть и понимать, в том числе то, что, возможно, выдумано, ибо нет свидетелей реального существования. То же, что раскрывается, может показать путь к чему-то лучшему или правильному. Гаунилон описывает явно не космос. Похоже на иудейское понимание мира-олама.

Он, Гаунилон, не понял мысли Ансельма, Бог которого неведом, как, собственно, и его, а потому Он «такое Иное, о чем больше и мыслить невозможно», но описал, как можно предположить, человеческую историю, созданную Богом, способ и условия существования мира определенным образом.

В такой истории нет ничего постоянного, стабильного, кроме того, что она история, начавшаяся во времена оны, в Иудее. Запад XVII в. сконцентрировал внимание на истории, сделал на ней акцент и весь мир в нее втянул, что соответствовало иудейской идее истории, и эта история исследовалась по правилам историки (наподобие поэтики), о чем в XVII в. писал Г.Й. Фоссий в книге «Искусство историки, или Сочинение о природе историки и истории, с рекомендациями, как писать историю, - общие размышления», перевод которой мы печатаем. Все остальное - наслоения, которые, конечно, надо исследовать, уже имея в виду новый социум. Любопытно, что никто уже не озабочен темой олама, даже в Израиле (как мне об этом написал Илья Дворкин), но кончается именно эта история мира сего. Ее консервация невозможна, ибо олам свободное движение мира, будущее, которого еще нет и которое неизвестно (природа может вытворить невесть что). История родилась как способ захвата и оценки схваченного. Она идет об руку с философией, ибо перебор вещей без философского ума невозможен. Это то, что было предметом внимания Александра Павловича. Это казус Огурцова.

\footnotetext{
2 Я сейчас не касаюсь анализа термина «ехistentia», важного для Ансельма, понимавшего под ним феномен, данный человеку как знак божественного существования чего-то большего, чем доступно его и физическому, и интеллектуальному зрению.
} 


\section{Литература}

1. Аврелий Августин. Об учителе / Пер. В.В.Бибихина // Памятники средневековой латинской литературы IV-VII веков / Отв. ред. С. С. Аверинцев и М. Л. Гаспаров, сост. О. Е. Нестерова. - М.: Наследие, 1998.

2. Ансельм Кентерберийский. Сочинения. - М.: Канон, 1995.

3. Бибихин В. В. Мир. - Томск: Водолей, 1995.

4. Неретина С. С. Слово и текст в средневековой культуре. История: миф, время, загадка. - М.: Гнозис, 1993. 2018.

5. Неретина С. С. Пауза созерцания. История: архаисты и новаторы. - М.: Голос,

6. Римская литература // Еврейская Электронная энциклопедия. Электронный pecypc:

https://www.google.ru/url?sa=t\&rct=j\&q=\&esrc=s\&source=web\&cd=\&ved=2ahUKEwjO2NK0 2L_0AhXrk4sKHbW1Avw4ChAWegQIFRAB\&url=https\%3A\%2F\%2Feleven.co.il\%2Fdiaspor a\%2Fcommunities\%2F13523\%2F\&usg=AOvVaw1Gg2VW72aUEBC8dnOpPogP. (Дата обращения: 30.11.2021.)

7. Савин А. Э. Критика иудаизма в ранних «теологических» сочинениях Гегеля // История философии. - 2018. Т. 23. № 2.

8. Цицерон. Об ораторе. Кн. II. 9 (36). Электронный ресурс: https://www.google.ru/url?sa=t\&rct=j\&q=\&esrc=s\&source=web\&cd=\&ved=2ahUKEwjVjPfz47 70AhXtyoKHQekBUEQFnoECAkQAQ\&url=http\%3A\%2F\%2Fancientrome.ru\%2Fantlitr\%2Ft.htm\%3 Fa\%3D1423777002\&usg=AOvVaw0bHgyAfGGpZ2JXcY-UXKns. （Дата обращения: 30.11.2021.)

9. Цицерон. Оратор, 39. Электронный ресурс: https://iknigi.net/. (Дата обращения: 30.11.2021.)

\section{References}

1. Anselmus Cantuariensis. Sochineniya [Works]. Moscow: Kanon, 1995. (In Russian.)

2. Aurelius Augustinus. "Ob uchitele" [About Teacher], trans. by V. V. Bibikhin, in: Pamiatniki srednevekovoy latinskoy literatury IV-VII vekov [Monuments of medieval Latin literature of the IV-VII centuries], ed. by S. S. Averintsev, M. L. Gasparov. Moscow: Nasledie, 1998. (In Russian.)

3. Bibikhin V. Mir [World]. Moscow: Vodoley, 1995. (In Russian.)

4. Cicero. $\mathrm{Ob}$ oratore [De oratore]. Vol. 2. URL: [https://www.google.ru/url?sa=t\&rct=j\&q=\&esrc=s\&source=web\&cd=\&ved=2ahUKEwjVjPfz4 770AhXtyoKHQekBUEQFnoECAkQAQ\&url=http\%3A\%2F\%2Fancientrome.ru\%2Fantlitr\%2Ft.htm\%3 
Fa\%3D1423777002\&usg=AOvVaw0bHgyAfGGpZ2JXcY-UXKns, accessed on 30.11.2021]. (In Russian.)

5. Cicero. Orator [Orator]. URL: [https://iknigi.net/, accessed on 30.11.2021]. (In Russian.)

6. Neretina S. Pausa sozertsaniya. Istoriya: arkhaisty i novatory [Contemplation pause. History: archaists and innovators]. Moscow: Golos, 2018. (In Russian.)

7. Neretina S. Slovo i tekst v srednevekovoy kulture. Istoriya: mif, vremia, zagadka [Word and text in medieval culture. History: myth, time, mystery]. Moscow: Gnosis, 1993. (In Russian.)

8. "Rimskaya literatura" [Roman literature], Jewish electronic encyclopedia. URL: [https://www.google.ru/url?sa=t\&rct=j\&q=\&esrc=s\&source=web\&cd=\&ved=2ahUKEwjO2NK 02L 0AhXrk4sKHbW1Avw4ChAWegQIFRAB\&url=https\%3A\%2F\%2Feleven.co.il\%2Fdiaspo ra\%2Fcommunities\%2F13523\%2F\&usg=AOvVaw1Gg2VW72aUEBC8dnOpPogP, accessed on 30.11.2021]. (In Russian.)

9. Savin A. Kritika iudaizma v rannikh "teologicheskikh" sochineniyakh Hegel [Criticism of Judaism in the early "theological" writings of Hegel]. History of philosophy, 2018, vol. 23, no. 2. (In Russian.)

\title{
Historia magistra vitae
}

Neretina S. S., DPhi, Institute of Philisophy of Russian Academy of Science, Chief Scientific Researcher, Professor, Ched-editor of journal "Vox", abaelardus@mail.com

\begin{abstract}
Absrtact: The article raises the question of understanding history not as a synthesis of the originally ancient Greek understanding of the world, the world of cosmic order and the Jewish Olam, but a palimpsest, where an erased other text is seen through the written text so that two dissimilar images of the world are manifested. The author examines the possibilities of such an understanding of history through the texts of "On the Orator" by Cicero, "Scholastic History" by Comestor and through a fragment of "Proslogion" by Anselm of Canterbury, who included in his work the objection to it of a certain monk Gaunilon. The idea of the world by V. V. Bibikhin seems to be a variant of resolving the problem of a dual understanding of history.
\end{abstract}

Keywords: history, world-space, world-olam, mind, speech, metaphor, nature, flood, gap, performativity. 